\title{
Osteopenia and Circulating Levels of Vitamin D Metabolites in Diabetes Mellitus
}

\author{
Hiroo IMURA, Yutaka SEINO, and Hitoshi ISHIDA \\ Second Division, Department of Medicine, Faculty of Medicine, \\ Kyoto University, Kyoto 606, Japan
}

Summary The degree of diabetic osteopenia and serum vitamin $\mathbf{D}$ metabolite levels were measured in 14 type 1 (insulin-dependent) and 168 type 2 (non-insulin-dependent) diabetic patients. Based on six indices obtained by microdensitometry, we found the bone mass in $28.6 \%$ of type 1 and $26.2 \%$ of type 2 diabetic patients to be decreased and in $14.3 \%$ and $11.9 \%$, respectively, the decrease was severe. Our method of analysis of bone mass has shown that diabetic osteopenia differs from typical osteoporosis in character. In addition, serum 24,25-dihydroxyvitamin D was significantly decreased both in type 1 and in type 2 diabetes ( $p<$ 0.01 ), but 1,25 -dihydroxyvitamin $\mathrm{D}$ was significantly decreased only in type 1 diabetes $(p<0.01)$ compared to the controls, being lower than that in type 2 diabetes $(p<0.05)$. On the other hand, 25-hydroxyvitamin $\mathrm{D}$ was similar to that of the controls, in both types of diabetes.

\section{Introduction}

In 1948, osteopenia was first reported in association with diabetes mellitus by Albright et al. (1), and recent studies have also shown that bone mass is occasionally decreased in both patients with type 1 (insulin-dependent) and with type 2 (non-insulin-dependent) diabetes mellitus (2-8). Since in alloxan- and streptozotocin(STZ)-induced diabetic rats bone mass is decreased $(9,10)$ and serum 1,25-dihydroxyvitamin $\mathrm{D} \quad\left(1,25-(\mathrm{OH})_{2} \mathrm{D}\right)$ levels are low (10-12), the osteopenia in experimental diabetes may be due to the altered vitamin D metabolism. However, the pathogenesis of diabetic osteopenia in humans remains unclear. Furthermore, little is known about vitamin D metabolism in patients with type 2 diabetes, although serum 1,25-(OH)$)_{2} \mathrm{D}$ levels have been reported to be low in young type 1 diabetic patients
(13). In addition, it has been suggested that 24,25dihydroxyvitamin $\mathrm{D}\left(24,25-(\mathrm{OH})_{2} \mathrm{D}\right)$ is essential for the formation of bone matrix and its mineralization (14). In the present study, therefore, we have examined the bone mass of adult type 1 and type 2 diabetics by microdensitometry of bone X-ray films, and have also measured their serum 25hydroxyvitamin $\mathrm{D}(25-\mathrm{OHD}), 24,25-(\mathrm{OH})_{2} \mathrm{D}$ and $1,25-(\mathrm{OH})_{2} \mathrm{D}$ levels to elucidate the relationship between diabetic osteopenia and altered vitamin $\mathbf{D}$ metabolism.

\section{Subjects and Methods}

Fourteen patients with clinically proven type 1 and 168 patients with type 2 diabetes mellitus were studied. There were 7 males and 7 females aged 17-38 in type 1 diabetes, and 84 males and 84 females aged $30-80$ in type 2 diabetes. All of the patients with type 1 diabetes had a past history of diabetic ketoacidosis and received insulin therapy. Fifty-one type 2 diabetic patients were satisfactorily treated by diets alone, 64 patients by oral hypoglycemic agents, and 53 patients by insulin to achieve good control of their blood glucose levels. All of them were defined as having type 2 diabetes, according to their onset of the disease, clinical symptoms, and laboratory findings. Sulfonylureas such as tolbutamide, tolazamide, chlorpropamide, glibenclamide, and acetohexamide were used as oral hypoglycemic agents. None of the subjcets had taken drugs known to interfere with vitamin D metabolism nor any vitamin preparations containing vitamin $D$. None of the patients had a past history of hepatic or renal disorders, and the hepatic enzymes, urea nitrogen, and creatinine levels were found to be within normal ranges, by blood analysis. As controls, 78 normal subjects, 51 males and 27 females aged 19-75, who had 
neither a family history of diabetes nor bone diseases were studied. They also had taken no drugs known to interfere with vitamin $\mathrm{D}$ metabolism nor vitamin preparations containing vitamin $D$. None of the subjects studied had a history of excessive sunlight exposure.

To determine the degree of osteopenia, X-ray films of both hands, taken with an aluminum step scale were analyzed by microdensitometer to examine the optical density at the center of the second metacarpal bone, according to the method of Inoue et al. (15). The bone width $(D)$, the bone marrow width $(d)$, cortex widths of the $\operatorname{radial}\left(d_{1}\right)$ and ulnar $\left(d_{2}\right)$ side, the density at the center of the bone marrow $\left(\Delta G S_{\min }\right)$, and peak densities on the $\operatorname{radial}\left(\Delta G S_{1}\right)$ and ulnar $\left(\Delta G S_{2}\right)$ side were measured. These values were used to determine six indices: 1) the metacarpal index (MCI), 2) the bone marrow width index $(d), 3)$ the center density index $\left(\Delta G S_{\min }\right)$, 4) the mean of $\Delta G S_{1}$ and $\Delta G S_{2}$-the side density index $\left.\left(\Delta G S_{\max }\right), 5\right)$ the index corresponding to the mineral content of the bone $(\Sigma G S / D, \Sigma G S=$ the integrated value of the density area calculated by computer), and 6) the densitometer pattern index. Each index was ranked by severity with a score of $0,1,2$, or 3 , according to the deviation from the regression line for each sex (age on the abscissa and measured values of the same indices on the ordinate) obtained from a previous study of 200 healthy subjects, 104 males and 96 females, aged 2-72. From the sum of the scores of the six indices, the degree of bone loss was divided into five classes: 1) without osteopenia (total score; 0-3), 2) the slightest degree (4-6), 3) the first degree $(7-9), 4)$ the second degree $(10-12)$, and 5) the third degree of osteopenia (13-18), according to the method of Inoue et al. (15). It has also been reported that MCI and $d$ are measurable with a coefficient of variation within $2-4 \%$, and the other indices within 3-7\% (15).

After an overnight fast, blood samples were taken from an antecubital vein, for the measurement of blood glucose and of vitamin D metabolites by the following methods, previously described in detail (16). Serum was extracted with methylene chloride : methanol $(1: 1)$ and the extract was chromatographed on a small Sephadex LH-20 column $(1.5 \times 7 \mathrm{~cm})$ using a solvent system of $n$-hexane : chloroform : methanol $(9: 1: 1)$. The metabolites were separated and purified by high pressure liquid chromatography(HPLC) on a Zorbax Sil column $(2.1 \times 250 \mathrm{~mm})$ with a flow rate of $0.4 \mathrm{ml} / \mathrm{min}$ and a solvent of $2.5 \%$ methanol in methylene chloride. 25-OHD, 24,25- $(\mathrm{OH})_{2} \mathrm{D}$, and $1,25-(\mathrm{OH})_{2} \mathrm{D}$ were eluted at the retention times of 3.5-6.5 min, 8.5-11.5 min, and 20-28 min, respectively. Rechromatography of the 25-OHD fraction was then performed in order to separate 25OHD from $25-\mathrm{OHD}_{3}$-26,23-lactone, using HPLC on a Zorbax Sil column $(2.1 \times 250 \mathrm{~mm})$ with a solvent of $6 \%$ isopropanol in $n$-hexane, and a flow rate of $0.4 \mathrm{ml} / \mathrm{min}$. Determination of 25-OHD and $24,25-(\mathrm{OH})_{2} \mathrm{D}$ were performed by the competitive protein binding assay, according to the methods of Haddad et al. $(17,18)$ with normal rat serum as the source of binding protein. Dextran-coated charcoal was used to separate the bound and free sterol. The sensitivity of the 25$\mathrm{OHD}$ and $24,25-(\mathrm{OH})_{2} \mathrm{D}$ assays were $0.1 \mathrm{ng} /$ tube and $0.1 \mathrm{ng} /$ tube, respectively. Quantitation of $1,25-(\mathrm{OH})_{2} \mathrm{D}$ was carried out using the assay of Eisman et al. $(19,20)$. The intestinal cytosol binding protein was prepared from vitamin D-deficient chicks. Separation of bound and free sterol was achieved using polyethylene glycol. The sensitivity of the $1,25-(\mathrm{OH})_{2} \mathrm{D}$ assay was $2 \mathrm{pg} /$ tube. Blood glucose was measured by the glucose oxidase method.

Statistical analysis for the significance of difference between groups was performed using unpaired $t$-test. Statistical analysis for the prevalence of osteopenia was done using Wilcoxon's rank sum test or Spearman's rank correlation test.

\section{Results}

The degree of osteopenia in both patients with type 1 and with type 2 diabetes is shown in Fig. 1. Of 14 type 1 diabetic patients, $6(42.9 \%)$ cases were without osteopenia, $4(28.6 \%)$ showed the slightest degree of osteopenia, $2(14.3 \%)$ had the first degree (I), $1(7.1 \%)$ had the second degree (II), and $1(7.1 \%)$ had the third degree (III) of osteopenia. Of 168 cases of type 2 diabetes, 93 $(55.4 \%)$ patients were without osteopenia, 31 $(18.5 \%)$ showed the slightest degree, $24(14.3 \%)$ had the first degree, $12(7.1 \%)$ had the second degree, and $8(4.8 \%)$ had the third degree. Accordingly, $28.6 \%$ of type 1 and $26.2 \%$ of type 2 diabetic patients had a definite decrease in bone mass (I-III) and, among them, $14.3 \%$ and $11.9 \%$ 


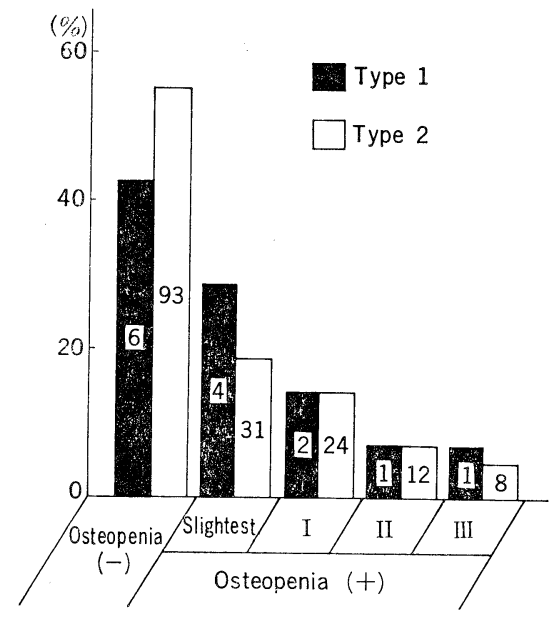

Fig. 1. Severity of osteopenia in type 1 and type 2 diabetic patients.

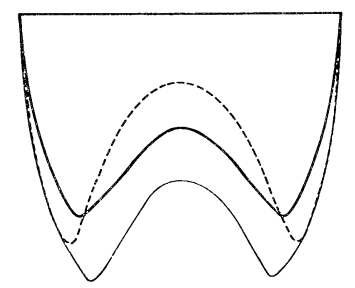

Fig. 2. Densitometer patterns indicating severely reduced bone mass of a representative female diabetic patient and a female age-matched typical osteoporotic patient. -, type 2 diabetes; ----, osteoporosis; - - healthy subjects.

had severely decreased (II-III) bone mass, respectively. There was no significant difference in the prevalence of osteopenia between patients with type 1 and type 2 diabetes examined in the present study. In contrast, none of the normal controls showed decreased bone mass of more than the first degree. Moreover, patients with type 2 diabetes taking oral agents tended to have less bone mass $(31.3 \%)$ than those on diets or insulin therapy $(23.5 \%$ and $22.6 \%$, respectively), although the difference was not statistically significant.

In the case of osteoporosis reported by Inoue et al. (15) using the same method, MCI decreased, $d$ increased, $\Delta G S_{\text {min }}$ decreased, and $\Sigma G S / D$ decreased, compared with the healthy subjects. Figure 2 shows the contrast between the densitometer pattern indicating severely reduced bone mass of a representative female diabetic patient and that
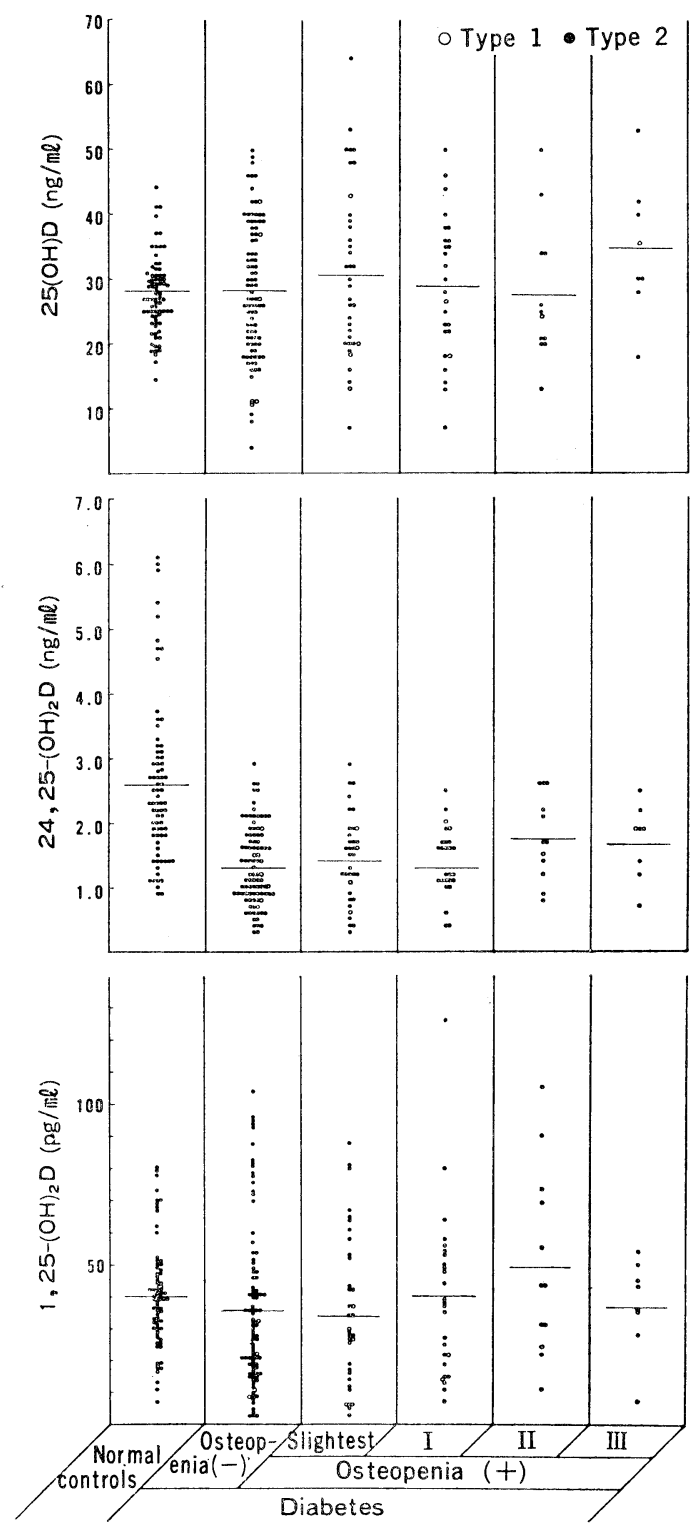

Fig. 3. Circulating levels of vitamin D metabolites and the degree of osteopenia in type 1 and type 2 diabetes.

of a female age-matched typical osteoporotic patient with fracture of the lumbar spine. The densitometer pattern of the hand in diabetic osteopenia resembles that of a typical osteoporotic, but there are some obvious differences between them. $\Delta G S_{\max }$ is reduced in diabetic osteopenia, whereas MCI, $\triangle G S_{\min }$, and $\Sigma G S / D$ are reduced in osteoporosis. When diabetic osteopenia was com- 
Table 1. Serum vitamin D metabolites in insulin-treated type 1 and type 2 diabetic patients on three types of treatment, and in control subjects.

\begin{tabular}{lcccc}
\hline & $n$ & $\begin{array}{c}25 \mathrm{OHD} \\
(\mathrm{ng} / \mathrm{ml})\end{array}$ & $\begin{array}{c}24,25-(\mathrm{OH})_{2} \mathrm{D} \\
(\mathrm{ng} / \mathrm{ml})\end{array}$ & $\begin{array}{c}1,25-(\mathrm{OH})_{2} \mathrm{D} \\
(\mathrm{pg} / \mathrm{ml})\end{array}$ \\
\hline $\begin{array}{l}\text { Type 1 diabetes } \\
\text { Type 2 diabetes }\end{array}$ & 14 & $24.2 \pm 3.1$ & $1.5 \pm 0.1^{\mathrm{a}}$ & $22.8 \pm 2.8^{\mathrm{a}, \mathrm{b}}$ \\
$\quad$ Diet & 51 & $28.6 \pm 1.5$ & $1.4 \pm 0.1^{\mathrm{a}}$ & $36.8 \pm 3.3$ \\
Drug & 64 & $30.2 \pm 1.4$ & $1.3 \pm 0.1^{\mathrm{a}}$ & $39.3 \pm 3.3$ \\
Insulin & 53 & $29.6 \pm 1.5$ & $1.4 \pm 0.1^{\mathrm{a}}$ & $38.0 \pm 3.7$ \\
$\quad$ Totals & 168 & $29.5 \pm 0.9$ & $1.4 \pm 0.1^{\mathrm{a}}$ & $38.2 \pm 2.0$ \\
Control & 78 & $28.0 \pm 0.7$ & $2.6 \pm 0.1$ & $40.1 \pm 1.9$ \\
\hline
\end{tabular}

Values of vitamin $D$ metabolites are the means \pm SE. a Significantly different from control subjects, $p<0.01$.

b Significantly different from type 2 diabetic patients on three types of treatment, $p<0.05$.

pared with age-matched osteoporosis, the same results described above were obtained for all ages.

Serum vitamin D metabolites in insulin-treated type 1 and type 2 diabetic patients of three treatment groups, and control subjects are shown in Table 1. Circulating levels of $24,25-(\mathrm{OH})_{2} \mathrm{D}$ and $1,25-(\mathrm{OH})_{2} \mathrm{D}$ were $1.5 \pm 0.1 \mathrm{ng} / \mathrm{ml}( \pm \mathrm{SE})$ and 22.8 $\pm 2.8 \mathrm{pg} / \mathrm{ml}$, respectively, in type 1 diabetic patients, being significantly lower than the values of $2.6 \pm 0.1 \mathrm{ng} / \mathrm{ml}$ and $40.1 \pm 1.9 \mathrm{pg} / \mathrm{ml}$, respectively, in control subjects $(p<0.01)$. Serum $1,25-(\mathrm{OH})_{2} \mathrm{D}$ in type 1 diabetes was significantly lower $(p<0.05)$ compared to that in type 2 diabetic patients of three treatment groups. In type 2 diabetes serum 24,25$(\mathrm{OH})_{2} \mathrm{D}$ concentration was $1.4 \pm 0.1 \mathrm{ng} / \mathrm{ml}$, also significantly lower than the value in the control $(p<0.01)$. On the other hand, circulating 25-OHD was similar to that of controls in both types of diabetes. Diabetic patients, with and without osteopenia, showed significantly lower serum 24,25 $(\mathrm{OH})_{2} \mathrm{D}$ levels than the controls $(p<0.01)$, but there was no apparent correlation between the degree of osteopenia and serum $24,25-(\mathrm{OH})_{2} \mathrm{D}$ levels (Fig. 3). There also was no significant difference in serum $24,25-(\mathrm{OH})_{2} \mathrm{D}$ concentrations among insulin-treated type 1 and type 2 diabetic patients of the three different treatment groups (Table 1). On the other hand, serum 25-OHD and 1,25$(\mathrm{OH})_{2} \mathrm{D}$ levels were not different among normal controls and diabetic patients, with or without osteopenia (Fig. 3). Both serum 25-OHD and $1,25-(\mathrm{OH})_{2} \mathrm{D}$ concentrations were the same in control subjects and all treatment groups of type 2 diabetes (Table 1).

\section{Discussion}

Several investigators $(2-8)$ have reported that bone mass is reduced in patients with type 1 and type 2 diabetes. The present study, using the microdensitometric method of bone X-ray films, confirmed a reduction of bone mass in diabetic patients when compared to that of healthy subjects. The microdensitometric method proposed by Anderson et al. (2I) is based on the principle similar to that of the photon absorption technique, using the X-ray instead of the $\gamma$-ray. The validity of this simple method has been assessed and established by Inoue et al. (15) by studying the relationship of six indices obtained from the method, with the severity of osteoporosis of the lumbar spine and iliac bone biopsy findings.

It is noteworthy that the densitometer pattern of severe diabetic osteopenia is different in several ways from that of severe typical osteoporosis. For example, the decrease of $\mathrm{MCl}$ (the relative width of the cortex) is less marked, whereas the decrease of $\Delta G S_{\max }$ (the mean maximal density of metacarpal bone) is more marked in diabetic osteopenia. These observations indicate that the cortical bone width and volume in diabetes is relatively well preserved, while the mineral content in the same volume of the cortex is decreased, compared to those of osteoporosis. Another possible interpretation of these data is less accelerated endosteal bone resorption in diabetic osteopenia, rather than in typical osteoporosis. In addition, Heath et al. (22) have reported that the risk of typical osteoporotic fractures of the vertebra, proximal hu- 
merus and femur, or distal forearm is not elevated among diabetic patients. These differences taken together suggest that diabetic osteopenia is a clinical entity, rather different from osteoporosis in character.

The pathogenesis of the reduction of bone mass in diabetes mellitus is still unclear. In the present study, we have found that circulating levels of $25-\mathrm{OHD}$ and $1,25-(\mathrm{OH})_{2} \mathrm{D}$ in type 2 diabetic patients are not different from those in normal subjects. It has been observed (23) that serum $24,25-(\mathrm{OH})_{2} \mathrm{D}$ concentrations are significantly lower in adult male insulin-treated diabetic patients. We have demonstrated further that serum 24,25$(\mathrm{OH})_{2} \mathrm{D}$ levels are significantly decreased in both adult male and female type 2 diabetic patients treated not only with insulin, but also with oral agents or diets alone. Furthermore, 24,25- $(\mathrm{OH})_{2} \mathrm{D}$ has been observed to be significantly low in adult insulin-treated type 1 diabetes. Although there was no correlation between the degree of osteopenia and serum levels of these vitamin D metabolites, there seems to be the possibility that the decrease in $24,25-(\mathrm{OH})_{2} \mathrm{D}$ might contribute in part to the pathogenesis of osteopenia in diabetes, since it has been postulated recently that $24,25-(\mathrm{OH})_{2} \mathrm{D}$ is a metabolite of vitamin $\mathrm{D}$, essential for the formation of bone matrix and its mineralization (14).

The mechanism responsible for decreased circulating $24,25-(\mathrm{OH})_{2} \mathrm{D}$ levels in both adult type 1 and type 2 diabetic patients remains obscure at present, but it may be a manifestation of the metabolic disorders due to insulin deficiency occurring in diabetes mellitus. There are several possible explanations for the decreased plasma $24,25-(\mathrm{OH})_{2} \mathrm{D}$ level in diabetic patients. First, the production of further metabolites or lactone bodies derived from 25-OHD is possibly so accelerated that $24,25-(\mathrm{OH})_{2} \mathrm{D}$ formation is decreased. Second, the conversion from $24,25-(\mathrm{OH})_{2} \mathrm{D}$ into further metabolites may be increased. Third, a metabolic disturbance due to insulin deficiency blocks the 24-hydroxylation step of 25-OHD. Further studies are needed to elucidate the mechanism of decreased $24,25-(\mathrm{OH})_{2} \mathrm{D}$ formation in diabetic patients. On the contrary, it has been recently reported that circulating $24,25-(\mathrm{OH})_{2} \mathrm{D}$ concentrations are elevated $(13,24)$ while $1,25-(\mathrm{OH})_{2} \mathrm{D}$ levels are low (13) in young (7-18 years of age) insulin-treated type 1 diabetic patients. The reason for the discrepancy between these observations and ours is not clear, but the difference in age and race or the different intake of calcium and vitamin D might be responsible for such discrepant results. Recently, Weiss et al. (25) have demonstrated that cartilage formation is inhibited and its calcification and resulting ossification are diminished and delayed in STZ-induced diabetic rats. It seems likely, therefore, that insulin is necessary in vivo for bone differentiation and mineralization. The presumed lower mineral content of the bone in diabetics, therefore, might be caused by a disturbance of bone mineralization, due to the relative or absolute lack of insulin, which is universally observed as the pathogenetic event in any type of diabetes. Further studies are needed to clarify the mechanism of altered mineral and vitamin D metabolism and the pathogenesis of diabetic osteopenia in human diabetes.

The authors are grateful to Hiroshi Nakahara, Hiroko Tachikawa, Masafumi Ohno, and Masayoshi Masaki for their skillful technical assistance.

\section{REFERENCES}

1) Albright, F. et al. (1948): Parathyroid Glands and Metabolic Bone Disease: Selected Studies, Baltimore, Williams \& Wilkins, p. 150.

2) Levin, M.E. et al. (1976): N. Engl. J. Med., 294, 241.

3) Rosenbloom, A.L. et al. (1977): Diabetes, 26, 1052.

4) McNair, P. et al. (1978): Diabetologia, 15, 87.

5) McNair, P. et al. (1979): Diabetologia, 17, 283.

6) McNair, P. et al. (1979): Acta Endocrinol. (Copenh.), 90, 463.

7) Santiago, J.V. et al. (1977): J. Clin. Endocrinol. Metab., 45, 845.

8) Shore, R.M. et al. (1981): Calcif. Tissue Int., 33, 455.

9) Brown, D.M. et al. (1977): Diabetes, 26, 370.

10) Shires, R. et al. (1981): J. Lab. Clin. Med., 97, 231.

11) Schneider, L.E. et al. (1977): Science, 196, 1452.

12) Spencer, E.M. et al. (1980): Endocrinology, 107, 300.

13) Frazer, T.E. et al. (1981): J. Clin. Endocrinol. Metab., 53, 1154.

14) Ornoy, A. et al. (1983): Nature, 276, 517.

15) Inoue, T. et al. (1983): J. Jpn. Orthop. Assoc., 57, 1923.

16) Ishida, H. et al. (1983): Acta Endocrinol. (Copenh.), $104,96$. 
17) Haddad, J.G. et al. (1971): J. Clin. Endocrinol. Metab., 33, 992.

18) Haddad, J.G., Jr. et al. (1977): Arch. Biochem. Biophys., 182, 390.

19) Eisman, J.A. et al. (1976): Science, 193, 1021.

20) Eisman, J.A. et al. (1976): Arch. Biochem. Biophys., 176, 235.

21) Anderson, J.B. et al. (1966): Br. J. Radiol., 39, 443.
22) Heath, H. et al. (1980): N. Engl. J. Med., 303, 567.

23) Christiansen, C. et al. (1982): Scand. J. Clin. Lab. Invest., 42, 487.

24) Witt, M.F. et al. (1983): J. Clin. Endocrinol. Metab., 57, 94.

25) Weiss, R.E. et al. (1980): Am. J. Physiol., 238 (Endocrinol. Metab., 1), E200. 